\title{
ResearchOnline@JCU
}

This is the Accepted Version of a paper published in the journal: Evolutionary Biology

Pillay, Neville, and Rymer, tasmin L. (2017) Preference for outbreeding in inbred Littedale's whistling rats Parotomys littledalei. Evolutionary Biology, 44 (1). pp. 21-30.

http://dx.doi.org/10.1007/s11692-016-9383-6 


\section{Preference for outbreeding in inbred Littledale's whistling rats Parotomys littledalei}

Inbred whistling rats prefer to outbreed. Pillay and Rymer

Neville Pillay ${ }^{1 *}$ and Tasmin L. Rymer ${ }^{1,2,3}$

${ }^{1}$ School of Animal, Plant and Environmental Sciences, University of the Witwatersrand, Private Bag 3, WITS 2050, South Africa

${ }^{2}$ College of Marine and Environmental Sciences, James Cook University, P. O. Box 6811, Cairns, QLD 4870, Australia

${ }^{3}$ Centre for Tropical Environmental and Sustainability Sciences, James Cook University, P. O. Box 6811, Cairns, QLD 4870, Australia

*Corresponding author: Neville.Pillay@wits.ac.za; Tel: +27117176459; Fax: +27117176494

\section{Acknowledgements}

We thank the Central Animal Services for technical assistance, and Northern Cape Nature Conservation for permission to collect animals. The comments by two anonymous reviewers greatly improved the manuscript. The authors declare no conflict of interest.

\footnotetext{
* This is the Accepted Version of a paper published in the journal Evolutionary Biology: Pillay, N. \& Rymer, T. L In press. Preference for Outbreeding in Inbred Littledale's Whistling Rats Parotomys littledalei. Evolutionary Biology.
} 


\begin{abstract}
Inbreeding is sometimes tolerated in species occupying patchy, unpredictable habitats, when it becomes too costly to outbreed. Although traits leading to inbreeding depression may be selected against, the accumulation of deleterious alleles from constant inbreeding might promote outbreeding. Littledale's whistling rat Parotomys littledalei occupies patchy habitats in arid western South Africa, and inbreeds in captivity without suffering inbreeding depression. We tested whether female whistling rats make different mate choice decisions based on their inbreeding status, by providing inbred and outbred females with male odours in four pairwise combinations: unrelated outbred $(\mathrm{r}=0)$ vs. either familiar littermate sibling $(\mathrm{r}=0.5)$, half-sibling $(r=0.25)$, first cousin $(r=0.125)$, or unrelated inbred $(r=0)$. Inbred females generally preferred unrelated males, but did not show a preference between unrelated males and first cousins. In contrast, outbred females did not generally show a preference, but preferred first cousins to unrelated males. In breeding trials, reproductive success (output and viability of young) of outbred females paired with unrelated or related males was equally high, whereas inbred females suffered reduced reproductive success when paired with closely-related males. Our results indicate that the inbreeding status of female whistling rats influences their decision to outbreed or inbreed, which might influence their fitness. While outbred whistling rats do not suffer inbreeding depression, the costs of constant inbreeding could promote outbreeding by inbred females. We propose that the choice to inbreed or outbreed in female whistling rats depends on their inbreeding status and the genetic relatedness of available mates, with outbreeding more likely to occur unless unrelated mates are not available.
\end{abstract}

Keywords: Genetic constitution, Inbreeding, Mate choice, Outbreeding, Patchy habitat 


\section{Introduction}

Inbreeding is typically associated with increased homozygosity (Charlesworth and Charlesworth 1987), loss of heterosis (Charlesworth and Charlesworth 1987; Ralls et al. 1988), and accumulation of deleterious mutations (Bataillon and Kirkpatrick 2000; Keller and Waller 2002). Consequently, inbreeding is rare in nature (Harvey and Ralls 1986; Pusey and Wolf 1996). There are times, however, when inbreeding occurs, suggesting either some adaptive advantage, even when there are high levels of inbreeding depression (Kokko and Ots 2006; Puurtinen 2011). Nonetheless, it is more likely that individuals are making the "best of a bad job" because opportunities to outbreed are not available (Batzli et al. 1977; Smith and Ivins 1983) and avoiding mating altogether incurs a significantly higher cost than the costs of inbreeding depression (Waser et al. 1986).

Typically, populations occupying patchy and ephemeral habitats will tolerate inbreeding, particularly when dispersal is costly (e.g. meadow voles Microtus pennsylvanicus, Batzli et al.1977; subsocial spiders Stegodyphus lineatus, Bilde et al. 2005). Under such circumstances, inbreeding would be beneficial due to the inclusive fitness benefits derived via incestuous matings (Lehmann and Perrin 2003). If inbreeding persists for extended periods, inbreeding depression can be reduced via the purging of deleterious alleles (e.g. ambrosia beetles Xylosandrus germanus, Peer and Taborsky 2005). However, the inevitable accumulation of deleterious alleles over generations might still occur (Frankham 1995; Devlin and Roeder 1999; Keller and Waller 2002) and thus outbreeding might be preferred when opportunities to do so arise. Several examples exist of animal species choosing to outbreed even when inbreeding does not necessarily result in reduced fitness, such as in the dwarf mongoose Helogale parvula 
(Keane et al. 1996) and red squirrel Tamiasciurus hudsonicus (Lane et al. 2007; but see Thünken et al. 2007, Wang and Lu 2011, Loyau et al. 2012). Even highly inbred naked mole rats Heterocephalus glaber, contrary to expectation, prefer to outbreed when given a choice, which likely increases reproductive success (Ciszek 2000). In populations tolerant of inbreeding, understanding the mate choice decisions of individuals will demonstrate whether inbreeding is simply an outcome of missed opportunity to outbreed or a strategic decision based on the inbreeding status (inbred vs. outbred) of individuals.

Animals recognise and avoid mating with kin by using behavioural and physiological mechanisms (Szulkin et al. 2013). Recognition by prior association is a common form of identifying kin, and occurs when young share a nest and associate with siblings and parents during a sensitive period (Schausberger 2007). For example, female African striped mice Rhabdomys sp. avoid mating with their fathers, which provide paternal care and have a close association with their daughters (Pillay 2002a). Another mechanism is where individuals use a template of themselves (i.e. self-referent matching) and/or of their kin or individuals encountered during development (Mateo 2010) against which they match cues of unfamiliar individuals to assess kinship (Hauber and Sherman 2001). For example, the house mouse Mus musculus domesticus avoids mating with close relatives that share similar major urinary proteins (MUPs), which provide a scent signal of genetic similarity (Sherborne et al. 2007).

Dispersal from the natal territory might also reduce the likelihood of inbreeding (Hargreaves and Eckert 2014). While inbreeding avoidance might be a consequence rather than a cause of dispersal (Greenwood and Harvey 1982; Armitage et al. 2011), emigration would limit contact between kin and possibly obviate the need to develop mechanisms for inbreeding avoidance (Ishibashi and Saitoh 2008). However, dispersing from the natal territory has inherent costs that 
could be substantially greater than the costs of inbreeding. Dispersal could lead to increased competition with established conspecifics in new home ranges (Cant et al. 2001) or selection against novel genotypes (Keller and Ross 1998). For example, juvenile pika Ochotona princeps in the harsh alpine Rocky Mountains suffer extreme aggression by neighbours during attempted dispersal, resulting in a high incidence of natal philopatry and, consequently, the potential for incestuous matings (Smith and Ivins 1983). Under such conditions, selection could favour philopatry (Lehmann and Perrin 2003) and mating with kin to gain some reproductive benefit, rather than avoid mating altogether, the ultimate cost of inbreeding avoidance (Waser et al. 1986). Importantly, females may prefer to mate with intermediately related individuals to maximize inclusive fitness while, at the same time, avoiding direct kin to minimise the costs of inbreeding depression (e.g. Barnard and Fitzsimons 1988; Keane 1990).

Our study is concerned with inbreeding in Littledale's whistling rat, Parotomys littledalei, a medium-sized (range 107-120g), diurnal, herbivorous murid rodent, endemic to the arid and semi-arid regions of southern Africa (Coetzee and Jackson 1999). Like all members of its subfamily Otomyinae, whistling rats produce small litters (1-4 offspring) of precocial young, which nipple-cling during early life (Pillay 2002b). Whistling rats are usually solitary, with individuals constructing and defending a complex warren system (mean \pm SD: $4.7 \pm 4.3 \mathrm{~m}$ in area, Coetzee and Jackson 1999) under bushes (whistling rat warrens never extend beyond the limits of a bush), particularly in vegetation associated with dry riverbeds (Coetzee 1969; Coetzee and Jackson 1999). These bushes are limiting resources and, while often clumped together (nearest neighbour distance is approximately $3.0 \pm 2.4 \mathrm{~m}$; Coetzee and Jackson 1999), clumps are situated wide apart, interspersed by large open sandy areas, which restricts whistling rat distribution within their geographical range (Jackson 2000). Travelling between bushes exposes 
whistling rats to diurnal predators (Skinner and Chimimba 2005) and harsh environmental conditions. Therefore, whistling rats do not readily forage beyond the confines of the warren (i.e. they are central place foragers; Coetzee and Jackson 1999)

Whistling rats can cohabit in larger bushes when population density increases (Coetzee and Jackson 1999), which, together with the reduced dispersal tendencies, might lead to inbreeding. Indeed, Pillay (2002c) found that 25 inbred (mother-son, brother-sister) pairs (originating from F1 generation outbred parents) did not appear to suffer obvious inbreeding depression in captivity. In that study, litter size, reproductive effort (a measure of investment in a litter relative to litter size; Millar 1977) and proportion of pairs reproducing was not different regardless of whether females were mated with brothers, sons or non-relatives, indicating no reproductive costs associated with inbreeding. Interestingly, outbred female whistling rats preferred siblings and half-sibling males to unrelated males in choice experiments, although there were no apparent reproductive benefits to inbreeding compared to outbreeding (Pillay 2002c). Choosing related over unrelated mates implies that females recognised kin, most likely through prior association.

Our aim in the current study was to establish the mate choice decisions of inbred and outbred female whistling rats for the odour cues of related and unrelated males, and then to assess the reproductive performance of these females when paired with related and unrelated males. We tested females because mate choice is more easily detected in female whistling rats (males do not show a preference between kin and non-kin, Pillay 2002c), and we used soiled bedding as the odour source, which is known to be an effective carrier of mate choice signals in this species (Pillay 2002c). To provide females with a full range of possible mating partners that they could encounter in nature, individual females were presented with pairwise combinations of odours of unrelated males vs. males of different relatedness, and unrelated but inbred males. We 
expected that the outbred and inbred females would make different mate choice decisions. We hypothesised that outbred females would prefer closely related males to unrelated males, as found by Pillay (2002c). However, we also hypothesised that inbred females would outbreed because of potential increased heterozygosity of offspring resulting from such pairings (Charlesworth and Charlesworth 1987; Devlin and Roeder 1999).

\section{Materials and Methods}

\section{Subjects}

30 adult whistling rats were live-trapped from several sites in the Succulent Karoo (Springbok region) of the Northern Cape Province, South Africa (29.40S, 17.53E). Sites were a minimum distance of $400 \mathrm{~m}$ apart because dispersal distances of whistling rats, although unknown, are unlikely to exceed $100 \mathrm{~m}$ (T. P. Jackson, pers. comm.). Whistling rats were transported to the Milner Park Animal Unit at the University of the Witwatersrand and maintained under partially controlled environmental conditions (15:9 h light: dark regime, lights on at 05:00 h; $22-25^{\circ} \mathrm{C}$; $30-70 \%$ relative humidity).

Pairings were established between individuals from different sites to reduce the likelihood of matings between closely related individuals. The offspring from these pairs (F1) were later paired with relatives (inbred) or unrelated offspring (outbred). The offspring of these pairings (F2) were used in experiments. Inbred whistling rats were derived either from mother-son pairings or brother-sister pairings, which were previously outbred (Pillay 2002c). Thus, all inbred F1 individuals had a coefficient of inbreeding (f) equal to 0.25 and a coefficient of relatedness (r) equal to 0.75 . All individuals were maintained in Lab-o-tec cages $(40 \times 25 \times 12$ $\mathrm{cm})$ and pairs were maintained in glass aquaria $(90 \times 30 \times 40 \mathrm{~cm})$ equipped with a nest box $(15 \mathrm{x}$ 
$15 \times 15 \mathrm{~cm}$ ). A layer of coarse wood shavings was provided as litter and nesting material comprised of hay. Twigs and PVC pipes were provided for enrichment. Cages and aquaria were washed, and wood shavings replaced weekly. Each rat received spinach, vegetable tops (e.g. carrot and beetroot), rabbit pellets (Epol, Pretoria West, South Africa) and water ad libitum.

\section{Mate choice}

Pillay (2002c) reported that female whistling rats make the same mate choice decisions for actual males as they do for male odours. When presented with either male odour (soiled bedding) only or the males themselves, females showed the same patterns of choice and, indeed, spent more time with the soiled bedding than the actual males themselves (Pillay 2002c). Therefore, we tested female preference for odour cues of males in three-way choice tests, conducted using a three choice chamber apparatus (Fig. 1). A neutral square Perspex area (40 x 40 x $20 \mathrm{~cm}$ ) was connected to three square choice chambers $(15 \times 15 \times 15 \mathrm{~cm})$ by PVC pipes $(6 \mathrm{~cm}$ internal diameter) at the middle of each side and the pipes had slots for cardboard partitions (Fig. 1), which were lifted during tests (see below). The floors of all chambers were covered in a layer of woodshavings. Prior to testing, approximately $30 \mathrm{~g}$ of wood shavings (soiled with urine, faeces and other bodily secretions) were collected from donor males using latex gloves. Bedding was soiled over a period of five days prior to collection. The soiled bedding was sealed in air-tight plastic bags and stored at $-15^{\circ} \mathrm{C}$ until use. Freezing of woodshavings does not influence odour volatility or quality (Pillay et al. 2006; Lenchova et al. 2008; Rymer and Pillay 2010).

Woodshavings were stored for a maximum of four days before use.

The preferences of individual oestrous females $(n=15$ inbred and $n=15$ outbred) were assessed by exposing them to the odours of males and a control in four pairwise combinations 
(treatments), using a repeated measures design: 1$)$ outbred unrelated $(\mathrm{r}=0)$ vs. littermate sibling $(\mathrm{r}=0.5) ; 2)$ outbred unrelated $(\mathrm{r}=0)$ vs. half-sibling $(\mathrm{r}=0.25) ; 3)$ outbred unrelated $(\mathrm{r}=0)$ vs. first cousin $(r=0.125)$; and 4) outbred unrelated $(r=0)$ vs. unrelated inbred $(r=0)$. Females were exposed to treatments in random sequence and to one treatment per day every 4-5 days to coincide with the female's oestrous cycle. Oestrous state of females was determined using vaginal smears; oestrous was assigned based on the presence of cornified epithelial cells.

Control odour consisted of unsoiled bedding (Pillay (2002c). Females had no contact with half-siblings, first cousins or unrelated individuals prior to tests, and were housed in rooms separated from siblings for at least 10 weeks prior to tests. Treatment 4 tested whether females could distinguish the inbreeding status of unrelated males (to control for a male's potential inbreeding status). All female subjects and donor males were sexually mature ( $>100$ days old; Pillay 2002b). Males were used twice but never with the same female. Five inbred and three outbred females became ill and could not complete all four treatments. Their data were excluded from experiments, leaving a total of 10 inbred and 12 outbred female in the final analysis.

Prior to testing, wood shavings from donor males were thawed at room temperature and placed into Petri dishes $(5.5 \mathrm{~cm}$ diameter $)$ in two of the choice chambers of the testing apparatus (Fig. 1). The control bedding was placed in a Petri dish in the third chamber. The position of the odour cues and control were randomly decided for each test. A test female was then placed in the neutral area and allowed to acclimate to the test apparatus for 10 minutes. Thereafter, the partitions to the choice chambers were removed and the duration of time (seconds) the female spent in each of the three chambers was video-recorded from above for 15 minutes under fluorescent light. No observers were present in the room during tests. Tests were conducted between 08h00-11h00 when whistling rats are active (Coetzee and Jackson 1999). After testing, 
the choice apparatus was cleaned with warm soapy water, swabbed with alcohol and air dried. The woodshavings were replaced.

We employed a similar three choice design per treatment used in a previous study in whistling rats (Pillay 2002c). Such a design presented females with a choice of odour cues of two males and a control, did not overly tax the decision making processes of the females, yet considered a range of genetically similar/dissimilar males. Using a sequential approach optimised the number of females used and created a repeated measures design to account for individual differences in mate choice. A sequential design could have influenced female responses over treatments because of learning and boredom. While female memory could have decayed during the 4-5 day break between tests, we, nonetheless, tested for the influence of the sequence of tests on responses by comparing the plots of times individual females spent with different choices in the first and again in the fourth treatment. In the first treatment, all inbred and $92 \%$ of outbred females made similar decisions to the overall pattern reported, despite being randomly assigned to treatments. In the fourth treatment, all females made choices in a similar pattern to the overall pattern. Therefore, female mate choice decisions were not influenced by the sequence of testing.

\section{Breeding experiments}

We paired inbred and outbred females with related and unrelated males from our breeding colony. Females were not used in mate choice experiments previously. Pairs had no physical or olfactory contact previously, having been housed in separate rooms. Females were assigned to five treatments ( $\mathrm{n}=15)$ differing in genetic relationship to their mates: (i) unrelated $(\mathrm{r}=0)$; (ii) littermate sibling ( $\mathrm{r}=0.5)$; (iii) half-sibling $(\mathrm{r}=0.25)$; (iv) first cousin $(\mathrm{r}=0.125)$; and (v) 
unrelated inbred $(\mathrm{r}=0)$. Breeding pairs were sexually mature adult $(>100$ days old $)$ virgins. All individuals were housed individually from 30 days old, so that full siblings did not make contact for several weeks before breeding.

Breeding pairs were established in glass aquaria under the same conditions mentioned above. As aggression is high in newly-established whistling rat breeding pairs (Pillay 2002c), pairs were separated with a wire mesh screen for two weeks, each partner having individual access to food, water and shelter (as described above). The mesh facilitated visual, olfactory and auditory contact between partners, but restricted physical contact. After two weeks, the pair was given access to each other and the entire aquarium. Both nest boxes were retained to allow options for solitary nesting or cohabitation. Aggression was minimal (occasionally chasing) or absent at this time, and pairs either nested together or separately. Males were removed from the breeding tank one week prior to parturition, because females become extremely aggressive to males (Pillay 2002c). Whistling rat gestation is 41 days (Pillay 2002b), so cages were checked every day from Day 39 post-pairing to 2-3 days after birth to detect any pup mortality. Pairs that had not produced a litter after 80 days were separated.

We compared the reproductive performance of inbred and outbred females in the treatment pairs by recording the proportion of pairs that reproduced, the litter size at birth (number of young present when the litter was first detected) and day 20, and litter sex ratio at day 2 and day 20. We recorded litter size and sex ratio at two time periods to account for any offspring mortality. We further investigated the viability of offspring in all treatments by recording offspring mass at day 2 and day 20 to calculate offspring growth rate. Young were weighed to the nearest $0.1 \mathrm{~g}$ every second day from day 2 to 20 days of age (physiological weaning occurs at day 12; Pillay 2002b). 


\section{Statistical Analysis}

All analyses were performed using Statistica 10 (Statsoft Inc, www.statsoft.com). We tested for normality (Shapiro-Wilks test) and homogeneity of variances (Levene's test) for the data prior to analysis. The model-level significance was set at $\alpha=0.05$ and all tests were two-tailed.

\section{Mate choice}

We used a general linear model (GLM) with a two-level repeated measures design to compare the duration of time females spent with the different odours and the control in each treatment. Female type (inbred vs. outbred) was the categorical predictor, treatment was the first level repeated measures variable and odour type (e.g. $r=0$ vs. $r=0.5$ vs. control) was the second level repeated measures variable. We used Fisher's HSD post-hoc tests to identify specific differences for categorical predictors. As small departures from sphericity can influence test size and test power (Boik 1981), we used Mauchley's sphericity test to determine sphericity. None of the variables were significant, indicating no sphericity: treatment $\left(\chi^{2}{ }_{5}=3.68, p=0.597\right)$, odour type $\left(\chi^{2}{ }_{2}=1.47, p=0.480\right)$ and treatment $\mathrm{x}$ odour type $\left(\chi^{2}{ }_{20}=20.29, p=0.440\right)$.

\section{Breeding experiments}

Logistic regressions were used to compare the number of pairs reproducing or sex ratio on day 2 and day 20 (dependent factors) in relation to treatment (categorical predictor); sex ratio was analysed twice to account for changes in litter size because of some deaths of young. A GLM with repeated measures design was used to compare female breeding status (inbred vs. outbred) for: 1) mean litter size at day 2 and day 20; and 2) litter mass on day 2 and day 20 to account for 
some deaths of young. Maternal body mass and litter size (for litter mass) were continuous predictors. Mean litter mass rather than individual mass was considered since individuals in a litter are not independent (Boonstra and Hochachka 1997), which also accounted for any deaths that occurred between days 2 and 20. Growth rates from day 2 to day 20 were calculated using the formula (LN mass day 20 - LN mass day 2)/18 days, and analysed using a GLM, in which female status and treatment were categorical predictors and maternal mass and litter size at day 20 (to account for deaths of young that occurred) were covariates. We used Fisher's HSD posthoc tests to identify specific differences for categorical predictors.

\section{Results}

\section{Mate choice}

Female inbreeding status $\left(F_{1,20}=1.65, P=0.214\right.$; see supplementary Table $\left.S 1\right)$, treatment $\left(F_{3,60}\right.$ $=1.44, P=0.240)$ and female status $x$ treatment $\left(F_{3,60}=0.73 . P=0.538\right)$ did not significantly influence overall olfactory preferences. However, choices made within treatments (i.e. odour type; $\left.F_{2,40}=157.03, P<0.001\right)$ and their second $\left(F_{2,40}=11.83, P<0.001 ; F_{6,120}=3.49, P=\right.$ $0.003)$ and third $\left(F_{6,120}=3.47, P=0.004\right)$ order interactions with female status and treatment were all significant predictors of time spent with odour cues. Post hoc tests showed that females generally showed a graded response for male odours and the unsoiled bedding (control), spending the least time with the control (Fig. 2). Specifically, inbred females spent significantly more time with the odour of unrelated males $(r=0$ unrelated) than full- $(r=0.5$; Treatment 1$)$ and half-siblings $(r=0.25$; Treatment 2; Fig. 2). However, they spent an equal duration of time with unrelated males $(\mathrm{r}=0$ unrelated $)$ and first cousins $(\mathrm{r}=0.125$; Treatment 3$)$ and unrelated inbred males ( $\mathrm{r}=0$; Treatment 4; Fig. 2). In contrast, outbred females spent an equal duration of 
time with both odour choices in all treatments, except Treatment $3(r=0.125)$, where they spent significantly more time with odour of first cousins than outbred males (Fig. 2).

\section{Breeding experiments}

Inbred females had significantly reduced reproductive success compared to outbred females (Wald $\chi^{2}{ }_{1}=4.33, P=0.037$ ), largely because of the reduced success in pairings of inbred females and brothers and half-brothers (Table 1). There were no significant treatment (Wald $\chi^{2}{ }_{4}=7.03, P$ $=0.134)$ and female status $\mathrm{x}$ treatment (Wald $\left.\chi^{2}{ }_{4}=6.36, P=0.174\right)$ effects. To confirm the fertility of unsuccessful inbred females paired with full $(r=0.5)$ and half-brothers $(r=0.25)$, we paired these females with unrelated outbred males from our colony. All 13 females originally paired with brothers reproduced and 10 originally paired with half-brothers produced litters.

Litter size on day 2 and 20 (Table 1$)$ was not significantly affected by female status $\left(F_{1,92}=\right.$ 3.34, $P=0.071)$, treatment $\left(F_{4,92}=1.67, P=0.165\right)$, and maternal mass $\left(F_{1,92}=0.60, P=\right.$ $0.441)$. However, there was a significant female status $\mathrm{x}$ treatment interaction $\left(F_{4,92}=3.00, P=\right.$ 0.022). Post hoc tests showed that inbred females mating with full $(r=0)$ and half $(r=0.25)$ brothers had reduced litter size compared to all other female status/treatment combinations (Table 1). There was no evidence of dead pups 2-3 days after birth. Some dead young were found 5-12 days after birth in some litters but no deaths occurred thereafter. In no cases were all young in a litter found dead. Therefore, litter size did not change significantly between day and 2 and 20 for all female status/treatment combinations $\left(F_{4,92}=0.93, P=0.448\right)$.

On both day 2 and day 20 , female status (day 2: Wald $\chi^{2}{ }_{1}=1.72, P=0.189$; day 20: Wald $\chi^{2}{ }_{1}$ $=0.805, P=0.370$ ), treatment (day 2 : Wald $\chi^{2}{ }_{4}=1.04, P=0.904 ;$ day $20: \chi^{2}{ }_{4}=0.75, P=0.944$ ) and female status $\mathrm{x}$ treatment (day 2 : Wald $\chi^{2}{ }_{4}=2.70, P=0.609$; day 20: Wald $\chi^{2}{ }_{4}=3.24, P$ 
$=0.518$ ) did not significantly influence the sex ratio of litters (Table 1). A closer scrutiny of the data showed that, compared to all other female status $\mathrm{x}$ treatment combinations, which showed a sex ratio of parity, outbred females produced significantly more male offspring when paired with their brothers $\left(\mathrm{r}=0.5 ; \chi^{2}{ }_{1}=4.74, P=0.029\right)$. There was also a trend for more male offspring in matings with half-brothers $\left(\mathrm{r}=0.25 ; \chi^{2}{ }_{1}=3.66, P=0.056\right)$.

Litter mass (Table 2$)$ was not significantly affected by female status $\left(F_{1,91}=0.30, P=\right.$ $0.561)$, treatment $\left(F_{4,91}=0.14, P=0.967\right)$, female status $\mathrm{x}$ treatment $\left(F_{4,91}=1.68, P=0.161\right)$ and maternal mass $\left(F_{1,91}=1.20, P=0.277\right)$. Litter mass was greater on day 20 than day $2\left(F_{4,91}=\right.$ 55.47, $P<0.001)$, which was part of the growth phase. Litter size $\left(F_{1,91}=50.36, P<0.001\right)$ was a significant continuous predictor, which showed a negative relationship between litter size and litter mass.

Growth rate (Table 2$)$ was not significantly influenced by female status $\left(F_{1,91}=0.12, P=\right.$ $0.734)$, treatment $\left(F_{4,91}=0.21, P=0.933\right)$, female status $x$ treatment $\left(F_{4,91}=1.70, P=0.156\right)$ or maternal mass $\left(F_{1,91}=1.00, P=0.319\right)$. Litter size $\left(F_{1,91}=22.69, P<0.001\right)$ was a significant continuous predictor, which showed a negative relationship with growth rate.

\section{Discussion}

The inbreeding status of female whistling rats influenced their mate choice decisions. Inbred females preferred unrelated males, regardless of their level of inbreeding, except for a similarity in choice for first cousins and unrelated males. In contrast, outbred females did not show a preference between closely related and unrelated males, except for a strong preference for first cousins over unrelated males. These mate choice decisions have fitness consequences as evident 
in the breeding studies. While outbred females did not appear to suffer reproductive costs (e.g. reduced litter size or litter mass), most inbred females incurred breeding costs by failing to produce offspring when paired with close kin (brothers and half-brothers), although matings with distantly related or unrelated inbred males were unaffected. Inbred females that failed to mate were not infertile. We could not tell whether these inbred females behaviourally avoided mating since there was no evidence of aggression in pairs that failed to mate, whether they failed to conceive (e.g. domestic cats Felis catus, Romagnoli et al. 2005), or they failed to carry pregnancies to term (e.g. Irish Holstein-Frisian dairy cows Bos taurus, McParland et al. 2007). The 5 (of 30) whistling rat females that bred with related males suffered reduced reproductive performance by producing significantly smaller litters.

The mate choice decisions of inbred whistling rat females together with their reproductive output in breeding tests indicates that they were choosing genetically different mates with consequent enhancement of reproductive success. Such mate choices are consistent with the "good genes" hypothesis, which posits that females should favour matings with males of better genetic quality (Boake 1986) to avoid genetic incompatibility (Trivers 1972; Zeh and Zeh 1996). Since inbreeding can be costly (Charlesworth and Charlesworth 1987; Keller and Waller 2002), outbreeding can increase the heterozygosity (Charlesworth and Charlesworth 1987; Devlin and Roeder 1999), and hence fitness (Ralls et al. 1988; Crnokrak and Roff 1999), of an inbred female's offspring.

The mate choice decisions of whistling rat females are governed by their inbreeding status and the inbreeding status of possible mates. Both inbred and outbred females shared the same social environment with their full brothers during early development up to 30 days of age before they were separated. Such prior association would have facilitated their recognition later. 
Females did not share the same social environments with half-brothers, first cousins and unrelated inbred males, so their ability to recognize kin without making prior contact suggests that female whistling rats used phenotypic matching of odour cues (Pillay 2002c). While we do not know the exact mechanism, the major histocompatibility complex (MHC; Tregenza and Wedell 2000) and major urinary proteins (MUPs; Hurst et al. 2001; Brennan and Kendrick) are two common mechanisms that rodents use to assess their own genetic constitution and that of a potential mate (Cheetham et al. 2007; Sherborne et al. 2007).

In a previous study of whistling rats, Pillay (2002c) found that females preferred the odour of siblings and half-siblings to unrelated males, whereas, in the current study, outbred females did not show a preference between unrelated males and siblings or half-siblings. In both studies, there were no immediate fitness consequences (based on litter size and characteristics) of mating with kin and non-kin, so mate choice decisions do not match reproductive success. Nonetheless, we cannot provide reasons for the discrepancy in mate choice since the study animals were derived from the same natural populations and housed under identical conditions. Interestingly, in the current study, inbred whistling rat females preferred unrelated males to full- and halfbrothers. Taken together, our findings from two studies suggest that females are capable of discriminating between males based on their relatedness, but can apparently not show a preference. Some rodent species can recognize related kin but choose not to treat them preferentially (e.g. Belding's ground squirrels Spermophilus beldingi, Mateo 2002).

Outbred female whistling rats preferred first cousins to outbred males, which suggests potential costs associated with outbreeding depression. Outbreeding depression can lead to genetic incompatibility and the breakdown of co-adapted gene complexes (Sagvik et al. 2005), and may be equivalent to the potential costs of inbreeding depression (e.g. increased 
homozygosity, Charlesworth and Charlesworth 1987; accumulation of deleterious mutations, Keller and Waller 2002). However, the choice of first cousins but not half and full siblings demonstrates optimal inbreeding, whereby females prefer males of intermediate relatedness (e.g. Barnard and Fitzsimons 1988; Keane 1990). While outbred female whistling rats did not appear to realise any direct fitness advantages (i.e. litter size and characteristics) from mating with first cousins, it is possible that outbred female whistling rats optimally inbreed to maximize their inclusive fitness (Puurtinen 2011). Interestingly, inbred whistling rat females did not show a preference between first cousins and unrelated males, even though they preferred unrelated males to full- and half-brothers. Not avoiding inbreeding, or optimally inbreeding, in whistling rats might be an adaptive response to living in an unpredictable, patchy environment (Batzli et al. 1977; Smith and Ivins 1983; Bilde et al. 2005). Over several generations, deleterious effects of inbreeding might be selected against (Peer and Taborsky 2005), favouring homozygous genotypes best suited to prevailing environments (i.e. local adaptation; Verhoeven et al. 2011). However, if females are inbred already, the costs of inbreeding might exceed the potential costs of outbreeding, and thus inbred females should outbreed to enhance their fitness when the opportunity arises.

The semi-arid Succulent Karoo biome inhabited by whistling rats is harsh and unpredictable, with highly variable temperatures and low water availability (Schradin and Pillay 2004), which influences resource distribution and availability (Schradin 2005). Whistling rats use underground burrows for protection from predators and to buffer against extreme environmental temperatures (Jackson 2000). These burrow systems are restricted to areas with comparatively high plant cover (Jackson 2000) but vegetation is patchily distributed and scarce (Schradin and Pillay 2004; 2005) and several rodent competitor species contest suitable nest sites (Jackson 2000). In 
addition, whistling rats are specialized herbivores (Coetzee and Jackson 1999), so that dispersal away from the natal nest could pose significant costs in lost foraging opportunities and exposure to predation. Furthermore, their short oestrous cycle (4-5 days), comparatively long gestation (Pillay 2002b) and solitary lifestyle means that mating opportunities for females are likely to be sequential and limited. Under these conditions, if the inbreeding load (defined as the rate at which fitness decreases with an increase in the inbreeding coefficient; Charlesworth and Willis 2009) is low, females should prefer to mate with relatives to maximize their inclusive fitness, which promotes male philopatry (Lehmann and Perrin 2003), as reported in pika (Smith and Ivins 1983) and banded mongoose Mungos mungo (Cant et al. 2001).

In conclusion, we showed that female whistling rats modify their mate choice decisions based on their inbreeding status, with inbred females choosing to outbreed and outbred females showing no choice, except for first cousins. Local adaptation in the Succulent Karoo could subsequently minimise negative inbreeding effects and, consequently, outbred females may not suffer any fitness costs by mating with related males. Furthermore, mating with distant relatives might increase the inclusive fitness of outbred females and related males, as well as minimise the costs of dispersal in males by promoting male philopatry. However, inbred females failed to reproduce in pairings with closely-related males and those that reproduced had reduced litter sizes, indicating longer term costs, observed as early as the second generation. Taken together, our data suggest that inbreeding and outbreeding occur concurrently in whistling rats, but are likely to occur alternately over successive generations, regulated by female choice, inbreeding load and possibly male dispersal. Future studies must consider the outcome of mate choice decisions in free-living whistling rats through genotyping and measuring fitness consequences of inbreeding and optimal outbreeding under challenging natural conditions. 


\section{Ethical Note}

This study complied with the laws and regulations in South Africa and was approved by the Animal Ethics Screening Committee of the University of the Witwatersrand (clearance no. $99 / 08 / 2 \mathrm{~A}$

\section{References}

Armitage, K. B., Van Vuren, D. H., Ozgul, A., \& Oli, M. K. (2011). Proximate causes of natal dispersal in female yellow-bellied marmots, Marmota flaviventris. Ecology, 92, 218-227.

Barnard, C. J., \& Fitzsimmons, J. (1988). Kin recognition and mate choice in mice: the effects of kinship, familiarity and social interference on intersexual interaction. Animal Behaviour, 36, $1078-1090$.

Bataillon, T., \& Kirkpatrick, M. (2000). Inbreeding depression due to mildly deleterious mutations in finite populations: size does matter. Genetical Research, 75, 75-81.

Batzli, G. O., Getz, L. L., \& Hurley, S. S. (1977). Suppression of growth and reproduction of microtine rodents by social factors. Journal of Mammalogy, 58, 583-591.

Benacerraf, B., \& Germain, R. N. (1978). The immune response genes of the major histocompatibility complex. Immunological Reviews, 38, 70-119.

Bilde, T., Lubin, Y., Smith, D., Schneider, J. M., \& Maklakov, A. A. (2005). The transition to social inbred mating systems in spiders: role of inbreeding tolerance in a subsocial predecessor. Evolution, 59, 160-174.

Boake, C. R. B. (1986). A method for testing adaptive hypotheses of mate choice. American Naturalist, 127, 654-666. 
Boik, R. J. (1981). A priori tests in repeated measures designs: effects of nonsphericity. Psychometrika, 46, 241-255.

Boonstra, R., \& Hochachka, W. M. (1997). Maternal effects and additive genetic inheritance in the collard lemming Dicrostonyx groenlandicus. Evolutionary Ecology, 11, 169-182.

Brennan, P. A., \& Kendrick, K. M. (2006). Mammalian social odours: attraction and individual recognition. Philosophical Transactions of the Royal Society of London B, 361, 2061-2078.

Cant, M. A., Otali, E., \& Mwanguyha, F. (2001). Eviction and dispersal in co-operatively breeding banded mongooses (Mungo mungo). Journal of. Zoology. London, 254, 155-162.

Charlesworth, D., \& Charlesworth, B. (1987). Inbreeding depression and its evolutionary consequences. Annual Review Of Ecology and Systematics, 18, 237-268.

Charlesworth, D., \& Willis, J. H. (2009). The genetics of inbreeding depression. Nature Reviews Genetics, 10, 783-796.

Cheetham, S. A., Thom, M. D., Jury, F., Ollier, W. E. R., Beynon, R. J., \& Hurst, J. L. (2007). The genetic basis of individual-recognition signals in the mouse. Current Biology, 17, 17711777.

Ciszek, D. (2000). New colony formation in the "highly inbred" eusocial naked mole-rat: outbreeding is preferred. Behavioral Ecology, 11, 1-6.

Coetzee, C. G. (1969). The distribution of mammals in the Namib desert and adjoining inland escarpment. Scientific Papers of the Namib Desert Research Station, 40, 23-36.

Coetzee, C. G., \& Jackson, T. P. (1999). The comparative behaviour and ecology of two species of Parotomys (Mammalia, Rodentia, Otomyinae) found in the arid areas of southern Africa. Journal of the Namibia Science Society, 47, 87-106.

Crnokrak, P., \& Roff, D. A. (1999). Inbreeding depression in the wild. Heredity, 83, 260-270. 
Devlin, B., \& Roeder, K. (1999). Genomic control for association studies. Biometrics, 55, 9971004.

Fisher, R. A. (1930). The genetical theory of natural selection. Oxford: Oxford University Press.

Frankham, R. (1995). Conservation genetics. Annual Review of Genetics, 29, 305-327.

Greenwood, P. J., \& Harvey, P. H. (1982). The natal and breeding dispersal of birds. Annual Review of Ecology and Systematics, 13, 1-21.

Hargreaves, A. L., \& Eckert, C. G. (2014). Evolution of dispersal and mating systems along geographic gradients: implications for shifting ranges. Functional Ecology, 28, 5-21.

Harvey, P. H., \& Ralls, K. (1986). Do animals avoid incest? Nature, 320, 575-576.

Hauber, M. E., \& Sherman, P. W. (2001). Self-referent phenotype matching: theoretical considerations and empirical evidence. Trends in Neuroscience, 24, 609-616.

Hughes, A. L., \& Nei, M. (1992). Maintenance of MHC polymorphism. Nature, 355, 402-403.

Hurst, J. L., \& Beynon, R. J. (2004). Scent wars: the chemobiology of competitive signalling in mice. BioEssays, 26, 1288-1298.

Hurst, J. L., Payne, C. E., Nevison, C. M., Marie, A. D., Humphries, R. E., Robertson, D. H. L., Cavaggioni, A., \& Beynon, R. J. (2001). Individual recognition in mice mediated by major urinary proteins. Nature, 414, 631-634.

Ishibashi, Y., \& Saitoh, T. (2008). Role of male-biased dispersal in inbreeding avoidance in the grey-sided vole (Myodes rufocanus). Molecular Ecology, 17, 4887-4896.

Jackson, T. P. (2000). Adaptation to living in an open arid environment: lessons from the burrow structure of the two southern African whistling rats, Parotomys brantsii and P. littledalei. Journal of Arid Environments, 46, 345-355. 
Keane, B. (1990). The effect of relatedness on reproductive success and mate choice in the white-footed mouse, Peromyscus leucopus. Animal Behaviour, 39, 264-273.

Keane, B., Creel, S. R., \& Waser, P. M. (1996). No evidence of inbreeding avoidance or inbreeding depression in a social carnivore. Behavioral Ecology, 7, 480-489.

Keller, L., \& Ross, K. G. (1998). Selfish genes: a green beard in the red fire ant. Nature, 394, $573-575$.

Keller, L. F., \& Waller, D. M. (2002). Inbreeding effects in wild populations. Trends in Ecology and Evolution, 17, 230-241.

Knapp, L. A., Ha, J. C., \& Sackett, G. P. (1996). Parental MHC antigen sharing and pregnancy wastage in captive pigtailed macaques. Journal of Reproductive Immunology, 32, 73-88.

Kokko, H., \& Ots, I. (2006). When not to avoid inbreeding. Evolution, 60, 467-475.

Lacy, R. C., \& Horner, B. E. (1997). Effects of inbreeding on reproduction and sex ratio of Rattus villosissimus. Journal of Mammalogy, 78, 877-887.

Lacy, R. C., Petric, A. M., \& Warneke, M. (1993). Inbreeding and outbreeding depression in captive populations of wild animal species. In N. W. Thornhill (Ed.), The natural history of inbreeding and outbreeding (pp. 352-374). Chicago: University of Chicago Press.

Lane, J. E., Boutin, S., Gunn, M. R., Slate, J., \& Coltman, D. W. (2007). Genetic relatedness of mates does not predict patterns of parentage in North American red squirrels. Animal Behaviour, 74, 611-619.

Lenchova, P., Roberts, S. C., \& Havlicek, J. (2008). Methods of human body odor sampling: the effect of freezing. Chemical Senses, 34, 127-138.

Lehmann, L., \& Perrin, N. (2003). Inbreeding avoidance through kin recognition: choosy females boost male dispersal. American Naturalist, 162, 638-652. 
Loyau, A., Cornuau, J. H., Clobert, J., \& Danchin, E. (2012). Incestuous sisters: mate preferences for brothers over unrelated males in Drosophila melanogaster. PLoS One, 7, e51293.

Mateo, J. M. (2002). Kin-recognition abilities and nepotism as a function of sociality. Proceedings of the Royal Society of London B, 269, 721-727.

Mateo, J.M. (2010) Self-referent phenotype matching and longterm maintenance of kin recognition. Animal Behaviour, 80, 929-935.

McParland, S., Kearney, J. F., Rath, M., \& Berry, D. P. (2007). Inbreeding effects on milk production, calving performance, fertility, and conformation in Irish Holstein-Friesians. Journal of Dairy Science, 90, 4411-4419.

Myers, P. (1978). Sexual dimorphism in size of vespertilionid bats. American Naturalist, 112, $701-711$.

Ober, C., Weitkamp, L. R., Cox, N., Dytch, H., Kostyu, D., \& Elias, S. (1997). HLA and mate choice in humans. American Journal of Human Genetics, 61, 497-504.

Peer, K., \& Taborsky, M. (2005). Outbreeding depression, but no inbreeding depression in haplodiploid ambrosia beetles with regular sibling mating. Evolution, 59, 317-323.

Pillay, N. (2002a). Father-daughter recognition and inbreeding avoidance in the striped mouse, Rhabdomys pumilio. Mammalian Biology, 67, 212-218.

Pillay, N. (2002b). Reproduction and postnatal development in Littledale's whistling rat Parotomys littledalei. Mammalia, 66, 71-82.

Pillay, N. (2002c). Inbreeding in Littledale's whistling rat Parotomys littledalei. Journal of Experimental Zoology, 293, 171-178. 
Pillay, N., Eborall, J., \& Ganem, G. (2006). Divergence of mate recognition in the African striped mouse (Rhabdomys pumilio). Behavioral Ecology, 17, 757-764.

Puurtinen, M. (2011). Mate choice for optimal (k)inbreeding. Evolution, 65, 1501-1505.

Pusey, A., \& Wolf, M. (1996). Inbreeding avoidance in animals. Trends in Ecology and Evolution, 11, 201-206.

Ralls, K., Ballou, J. D., \& Templeton, A. (1988). Estimates of lethal equivalents and the cost of inbreeding in mammals. Conservation Biology, 2, 185-193.

Romagnoli, S. (2005). Failure to conceive in the queen. Journal of Feline Medicine and Surgery, 7, 59-63.

Rymer, T., \& Pillay, N. (2010). Female mate choice for paternal care behaviour in African striped mice Rhabdomys pumilio: the role of experience. Behaviour, 147, 1101-1119.

Sagvik, J., Uller, T., \& Olsson, M. (2005). Outbreeding depression in the common frog, Rana temporaria. Conservation Genetics, 6, 205-211.

Schausberger, P. (2007). Kin recognition by juvenile predatory mites: prior association or phenotype matching? Behavioural Ecology and Sociobiology, 62, 119-125.

Schradin, C. (2005). When to live alone and when to live in groups: Ecological determinants of sociality in the African striped mouse (Rhabdomys pumilio, Sparrman, 1784). Belgian Journal of Zoology, 135, 77-82.

Schradin, C., \& Pillay, N. (2004). The striped mouse (Rhabdomys pumilio) from the succulent karoo of South Africa: A territorial group living solitary forager with communal breeding and helpers at the nest. Journal of Comparative Psychology, 118, 37-47.

Schradin, C., \& Pillay, N. (2005). Demography of the striped mouse (Rhabdomys pumilio) in the succulent karoo. Mammalian Biology, 70, 84-92. 
Sherborne, A. L., Thom, M. D., Paterson, S., Jury, F., Ollier, W. E. R, Stockley, P., Beynon, R. J., \& Hurst, J. L. (2007). The genetic basis of inbreeding avoidance in house mice. Current Biology, 17, 2061-2066.

Skinner, J. D., \& Chimimba, C. T. (2005). The mammals of the southern African subregion. Cape Town: Cambridge University Press.

Smith, A. T., \& Ivins, B. L. (1983). Colonization in a pika population: dispersal vs. philopatry. Behavioural Ecology and Sociobiology, 13, 37-47.

Szulkin, M., Stopher, K. V., Pemberton, J. M., \& Reid, J. M. (2013). Inbreeding avoidance, tolerance, or preference in animals? Trends in Ecology and Evolution, 28, 205-211.

Takahata, N., Satta, Y., \& Klein, J. (1992). Polymorphism and balancing selection at major histocompatibility complex loci. Genetics, 130, 925-938.

Thünken, T., Bakker, T. C. M., Baldauf, S. A., \& Kullmann, H. (2007). Active inbreeding in a cichlid fish and its adaptive significance. Current Biology, 17, 225-229.

Tregenza, T., \& Wedell, N. (2000). Genetic compatibility, mate choice and patterns of parentage: Invited review. Molecular Ecology, 9, 1013-1027.

Trivers, R. L. (1972). Parental investment and sexual selection. In B. Campbell (Ed.), Sexual selection and the descent of man, 1871-1971 (pp. 136-179). Chicago: Aldine-Atherton.

Trivers, R. L., \& Willard, D. E. (1973). Natural selection of parental ability to vary the sex ratio of offspring. Science, 179, 90-92.

Verhoeven, K. J. F., Macel, M., Wolfe, L. M., \& Biere, A. (2011). Population admixture, biological invasions and the balance between local adaptation and inbreeding depression. Proceedings of the Royal Society of London B, 278, 2-8. 
Wang, C., \& Lu, X. (2011). Female ground tits prefer relatives as extra-pair partners: driven by kin-selection? Molecular Ecology, 20, 2851-2863.

Waser, P. M., Austad, S. N., \& Keane, B. (1986). When should animals tolerate inbreeding? American Naturalist, 128, 529-537.

Wittzell, H., Madsen, T., Westerdahl, H., Shine, R., \& von Schantz, T. (1999). MHC variation in birds and reptiles. Genetica, 104, 301-309.

Zeh, J. A., \& Zeh, D. W. (1996). The evolution of polyandry i: intragenomic conflict and genetic incompatibility. Proceedings of the Royal Society of London B, 263, 1711-1717.

Zeh, J. A., \& Zeh, D. W. (1997). The evolution of polyandry II: post-copulatory defences against genetic incompatibility. Proceedings of the Royal Society of London B, 264, 69-75. 
1 Table 1. Breeding success (number of pairs that produced a litter out of the total number of pairs) and litter characteristics (mean

$2( \pm$ SE) litter size at day 2 and at day 20 and litter sex ratio at day 2 and day 20) of inbred and outbred female whistling rats Parotomys

3 littledalei in five breeding treatments with unrelated $(\mathrm{r}=0$, outbred or inbred $)$ and related $(\mathrm{r}=0.5 ; 0.25 ; \mathrm{r}=0.125)$ males. Litter size

4 and sex ratio data include only young counted on day 2 and on day 20 respectively.

\begin{tabular}{|c|c|c|c|c|c|c|c|c|c|c|}
\hline \multirow[t]{2}{*}{ Treatment } & \multicolumn{2}{|c|}{$\begin{array}{c}\text { Successful pairs/ } \\
\text { total pairs }\end{array}$} & \multicolumn{2}{|c|}{ Litter size day 2} & \multicolumn{2}{|c|}{ Litter size day 20} & \multicolumn{2}{|c|}{$\begin{array}{l}\text { Sex ratio day } 2 \\
\text { (male: female) }\end{array}$} & \multicolumn{2}{|c|}{$\begin{array}{l}\text { Sex ratio day } 20 \\
\text { (male: female) }\end{array}$} \\
\hline & Inbred & Outbred & Inbred & Outbred & Inbred & Outbred & Inbred & Outbred & Inbred & Outbred \\
\hline $\mathbf{r}=\mathbf{0}$ (outbred) & $13 / 15$ & $11 / 15$ & $2.38(0.19)$ & $2.36(0.21)$ & $2.07(0.76)$ & $2.18(0.22)$ & $13: 19$ & $12: 14$ & $13: 19$ & $12: 14$ \\
\hline$r=0.5$ & $2 / 15$ & $10 / 15$ & $1.00(0.00)$ & $2.70(0.21)$ & $1.00(0.00)$ & $2.70(0.21)$ & $1: 1$ & $19: 8$ & $1: 1$ & $19: 8$ \\
\hline$r=0.25$ & $3 / 15$ & $14 / 15$ & $1.33(0.33)$ & $2.36(0.13)$ & $1.33(0.33)$ & $2.00(0.18)$ & $2: 3$ & $22: 11$ & $2: 3$ & $22: 11$ \\
\hline$r=0.125$ & $11 / 15$ & $12 / 15$ & $2.36(0.20)$ & $2.42(0.20)$ & $2.09(0.21)$ & $2.42(0.20)$ & $13: 13$ & $13: 16$ & $13: 13$ & $13: 16$ \\
\hline $\mathbf{r}=\mathbf{0}$ (inbred) & $13 / 15$ & $14 / 15$ & $2.54(0.26)$ & $2.29(0.22)$ & $2.46(0.24)$ & $2.00(0.23)$ & $15: 18$ & $15: 17$ & $15: 18$ & $15: 17$ \\
\hline
\end{tabular}

5 
1 Table 2. Mean ( \pm SE) litter mass and growth rates of offspring produced by successfully

2 reproducing inbred and outbred female whistling rats Parotomys littledalei in five breeding

3 treatments with unrelated $(\mathrm{r}=0$; outbred or inbred) and related $(\mathrm{r}=0.5 ; 0.25 ; \mathrm{r}=0.125)$ males.

4 Samples sizes are given in Table 1. Litter mass and growth rate data considered only young 5 counted on day 2 and day 20 respectively.

6

\begin{tabular}{|l|c|c|c|c|c|c|}
\hline \multirow{2}{*}{ Treatment } & \multicolumn{2}{|c|}{ Litter mass (g) day 2} & \multicolumn{2}{c|}{ Litter mass (g) day 20 } & \multicolumn{2}{c|}{ Growth (d/day) } \\
\cline { 2 - 7 } & Inbred & Outbred & Inbred & Outbred & Inbred & Outbred \\
\hline $\mathbf{r = 0}$ (outbred) & $12.36(0.51)$ & $12.47(0.55)$ & $51.82(2.92)$ & $46.58(3.17)$ & $2.19(0.16)$ & $1.90(0.18)$ \\
\hline $\mathbf{r}=\mathbf{0 . 5}$ & $12.95(1.29)$ & $12.71(0.58)$ & $50.15(7.45)$ & $46.81(3.33)$ & $2.06(0.42)$ & $1.89(0.19)$ \\
\hline $\mathbf{r = 0 . 2 5}$ & $13.78(1.06)$ & $11.02(0.49)$ & $52.58(6.08)$ & $48.73(2.81)$ & $2.16(0.34)$ & $2.11(0.16)$ \\
\hline $\mathbf{r = 0 . 1 2 5}$ & $12.27(0.55)$ & $11.75(0.53)$ & $55.13(3.18)$ & $44.12(3.04)$ & $2.38(0.19)$ & $1.80(0.17)$ \\
\hline $\mathbf{r = 0}$ (inbred) & $11.58(0.51)$ & $11.79(0.49)$ & $45.72(2.92)$ & $53.50(2.82)$ & $1.89(0.17)$ & $2.32(0.16)$ \\
\hline
\end{tabular}

7 


\section{List of figures}

2 Fig. 1 Three chamber apparatus used for mate choice experiments in female whistling rat

3 Parotomys littledalei. An oestrous female was placed in the neutral area (A). Petri dishes with

4 odour samples from males or unsoiled bedding were placed into the centre of each choice

5 chamber (B, C, D) in random order. Stipple lines indicate slots for cardboard partitions

6 Measurements are in $\mathrm{cm}$.

8 Fig. 2 Mean \pm SE duration of time (s) spent by inbred and outbred female Littledale's whistling 9 rats Parotomys littledalei in chambers containing unrelated ( $\mathrm{r}=0$ refers to unrelated outbred 10 and $\mathrm{r}=0$ i refers to unrelated inbred), related $(\mathrm{r}=0.5 ; 0.25 ; \mathrm{r}=0.125)$ or control bedding in 11 four treatments. Points marked by different letters are significantly different. 